\title{
SOCIOLOGY FOR PHARMACISTS
}




\section{Sociology for Pharmacists}

An Introduction

Geoffrey Harding

Sarah Nettleton

Kevin Taylor 
All rights reserved. No reproduction, copy or transmission of this publication may be made without written permission.

No paragraph of this publication may be reproduced, copied or transmitted save with written permission or in accordance with the provisions of the Copyright, Designs and Patents Act 1988, or under the terms of any licence permitting limited copying issued by the Copyright Licensing Agency, 90 Tottenham Court Road, London W1P 9HE.

Any person who does any unauthorised act in relation to this publication may be liable to criminal prosecution and civil claims for damages.

First published 1990 by THE MACMILLAN PRESS LTD

Houndmills, Basingstoke, Hampshire RG21 2XS and London

Companies and representatives

throughout the world

ISBN 978-0-333-49765-4

ISBN 978-1-349-21149-4 (eBook)

DOI 10.1007/978-1-349-21149-4

A catalogue record for this book is available from the British Library.

Reprinted 1993 
To Sally Ann and Pauline 


\section{Contents}

List of Tables

Acknowledgement

$\mathbf{x}$

Preface

xii

xiii

1 Social Science and Pharmacy 1

What is Sociology? 3

Sociology as Applied to Pharmacy 5

2 The Development of Pharmacy: Setting the Scene 7

Hospital Pharmacy $\quad 8$

Community Pharmacy 9

The Pharmacist's 'Extended Role' 11

3 Sociological Understanding of Health and Illness

Illness as a Social Concept

Frequency of Symptoms: The Symptom Iceberg

Illness Behaviour

$4 \quad$ Lay Health Beliefs and 'Help Seeking' Behaviour

Initiating a Consultation with a Health Care Professional

Lay Referral Systems

Lay Health Care Workers 30

Lay Health Beliefs 31

The Sick Role 35

Relationships Between Patients and

Health Care Professionals

Consulting a General Practitioner $\quad 41$

Consulting a Pharmacist 
5 Social Factors and Health 47

Measuring Health 47

Perspectives on Health 50

The Medical Model of Health and Disease 53

The Socio-Environmental Model of Health and Disease $\quad 53$

6 Social Inequalities and Health 55

Gender and Health 55

Ethnicity and Health 57

The Concept of Social Class $\quad 59$

Social Class Classification $\quad 60$

The Limitations of Social Classification Systems 61

Social Class and Health: The Evidence 62

Unemployment and Health 65

Social Class and Health: The Explanations 67

7 Is Pharmacy a Profession? 73

Sociological Approaches to Professionalisation 73

Core Features of a Profession $\quad 75$

The Process of Professionalisation $\quad 76$

The Emergence of Pharmacy $\quad 78$

$\begin{array}{ll}\text { Pharmacy as a Profession } & 79\end{array}$

8 Health Education and Health Promotion 84

Health Policy and Health Education 84

Defining Prevention $\quad 85$

Defining Health Education $\quad 86$

Defining Health Promotion 89

Sociological Approaches to Health
Education

9 Pharmacists and Health Promotion 95

Pharmacy Based Health Education

Campaigns 95

Enhancing Drug Compliance $\quad 101$ 
Health Promotion Strategies and Drug Misuse

Drug Misuse, AIDS Prevention and Pharmacists Injecting Equipment Exchange Schemes

10 Social Research Methods 108

Methods of Social Analysis 109

Sampling 113

Interviews and Social Surveys 114

Self-completed Questionnaire Surveys 116

The Response Rate 117

A Guide to Survey Question Form and Content

Analysing Data

Validity and Causality 


\section{List of Tables}

2.1 Membership of the Pharmaceutical Society by occupation

2.2 The pharmacist's 'extended role'

3.1 Incidence of reported illness over a two-week and twelve-month period

3.2 The response of adults to minor ailments

4.1 Uptake of health services as influenced by the lay referral system

4.2 Analysis of the roles of patients and doctors as suggested by Parsons

4.3 Szasz and Hollender's three models of patienthealth professional relationship

6.1 Longstanding illness by social class and sex in Great Britain

6.2 Expectation of life at birth by sex, from 1900-79, in England and Wales

6.3 Comparison of mortality rates: specific mortality by racial group (England and Wales)

6.4 The Registrar General's social class classification

6.5 Stillbirth and mortality rates in the first year of life

6.6 Comparison of infant mortality rates for member countries of the European Community

6.7 Mortality rates of men and women in different regions of Britain, 1979-80, and 1982-83

6.8 Weekly food expenditure as a function of weekly household income

9.1 Nature of enquiries to pharmacists 96

9.2 Symptom enquiries presented to pharmacists 
9.3 Pharmacists' responses to symptom enquiries

9.4 Over the counter medicine enquiries presented to pharmacists

9.5 Dispensed medicine enquiries presented to pharmacists 


\section{Acknowledgement}

We are grateful to Boots The Chemists for their assistance towards the production of this book. We would also like to thank Ann Oakley for her comments on an earlier draft of the book. 


\section{Preface}

This book is intended to acquaint the reader with some of the basic theories and concepts of medical sociology and their application to aspects of pharmaceutical service delivery. We have written this book in response to the recognition that social science can contribute towards equipping pharmacists for practice in the 1990s and beyond. We have adopted an inter-disciplinary approach to the preparation of this book. The topics covered are by no means exhaustive. Rather we have addressed those issues which we consider collectively, as pharmacist, sociologists, and as health care consumers, to be most important.

In chapter one we introduce the subject of sociology and discuss the developments within pharmacy which have led to calls for subjects such as sociology to be included in the pharmacy undergraduate degree curriculum. In chapter two we examine pharmacists' roles and activities in the light of the Nuffield Report on Pharmacy. We also examine the implications of that report and of government proposals on health policy, for the future practice of pharmacy. Sociological perspectives on the experience of illness, and illness behaviour are explored in chapters three and four, and we note that the presence of symptom(s) alone may not result in an individual seeking help or treatment from a health professional. Chapters five and six consider the ways in which health status, and the experience of illness are influenced by such factors as social class, gender and ethnicity. The potentially contentious issue of whether pharmacy, when examined from a sociological perspective, can or can not be considered a full profession is covered in chapter seven. In chapters eight and nine we consider the issues of health education and the pharmacist's role in health promotion. Chapter ten is devoted to a brief introduction to some methodological issues in social research, and incorporates some guidance as to how these issues may be applied to research in the social aspects of pharmacy.

As such we hope this book will be used by students, academic pharmacists and practising pharmacists alike. Moreover, we hope it will stimulate the development of sociologically informed research in social aspects of the practice of pharmacy. 